October 2004 - NREL/CP-500-36900

\title{
Wind Turbine Post-Stall Airfoil Performance Characteristics Guidelines for Blade-Element Momentum Methods
}

\section{Preprint}

J. Tangler

National Renewable Energy Laboratory

J. David Kocurek

Computational Methodology Associates

To be presented at the $43^{\text {rd }}$ AIAA Aerospace Sciences Meeting and Exhibit Reno, Nevada January 10-13, 2005
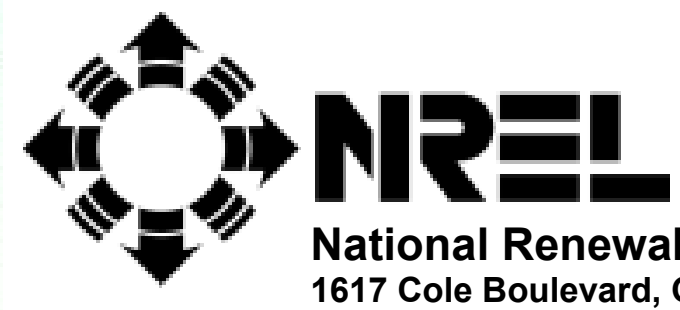

National Renewable Energy Laboratory 1617 Cole Boulevard, Golden, Colorado 80401-3393 303-275-3000 • www.nrel.gov

Operated for the U.S. Department of Energy

Office of Energy Efficiency and Renewable Energy

by Midwest Research Institute $\bullet$ Battelle

Contract No. DE-AC36-99-G010337 


\section{NOTICE}

The submitted manuscript has been offered by an employee of the Midwest Research Institute (MRI), a contractor of the US Government under Contract No. DE-AC36-99G010337. Accordingly, the US Government and MRI retain a nonexclusive royalty-free license to publish or reproduce the published form of this contribution, or allow others to do so, for US Government purposes.

This report was prepared as an account of work sponsored by an agency of the United States government. Neither the United States government nor any agency thereof, nor any of their employees, makes any warranty, express or implied, or assumes any legal liability or responsibility for the accuracy, completeness, or usefulness of any information, apparatus, product, or process disclosed, or represents that its use would not infringe privately owned rights. Reference herein to any specific commercial product, process, or service by trade name, trademark, manufacturer, or otherwise does not necessarily constitute or imply its endorsement, recommendation, or favoring by the United States government or any agency thereof. The views and opinions of authors expressed herein do not necessarily state or reflect those of the United States government or any agency thereof.

Available electronically at http://www.osti.gov/bridge

Available for a processing fee to U.S. Department of Energy and its contractors, in paper, from:

U.S. Department of Energy

Office of Scientific and Technical Information

P.O. Box 62

Oak Ridge, TN 37831-0062

phone: 865.576 .8401

fax: 865.576 .5728

email: mailto:reports@adonis.osti.gov

Available for sale to the public, in paper, from:

U.S. Department of Commerce

National Technical Information Service

5285 Port Royal Road

Springfield, VA 22161

phone: 800.553 .6847

fax: 703.605.6900

email: orders@ntis.fedworld.gov

online ordering: http://www.ntis.gov/ordering.htm 


\title{
Wind Turbine Post-Stall Airfoil Performance Characteristics Guidelines for Blade-Element Momentum Methods
}

\author{
James L. Tangler \\ National Renewable Energy Laboratory \\ james_tangler@nrel.gov
}

\author{
J. David Kocurek \\ Computational Methodology Associates \\ drtomcat@msn.com
}

\begin{abstract}
The objective of this study was to provide post-stall airfoil data input guidelines for the prediction of peak and post-peak rotor power when using blade-element momentum theory. A steady-state data set from the Unsteady Aerodynamic Experiment (UAE) rotor test was used to provide guidelines for the development of a global post-stall method for the prediction of post-stall 3-D airfoil characteristics to be used with 2-D airfoil data. Based on these UAE data, methods to emulate the 3-D aerodynamics in the post-stall region were explored. Also suggested are experimental tests needed to better understand the 3-D flow physics and to quantify needed theory or empirical factors for a global post-stall approach to support blade-element momentum methods.
\end{abstract}

\section{Introduction}

The prediction of peak rotor power and post-peak power is important in the design of constant-speed and variablespeed stall-regulated rotors. For small turbines, the latter approach is seen as a viable means of controlling peak power with power electronics in lieu of more expensive variable-pitch control or noise-producing rotor furling.

Analytical and experimental studies ${ }^{1-16}$ have been directed toward understanding the complex 3-D flow physics that are associated with the post-stall region following peak rotor power. A shortcoming of the experimental studies has been the lack of a method for determining the blade's angle of attack $(\alpha)$ distribution so that normal and tangential force coefficients $\left(\mathrm{C}_{\mathrm{n}}\right.$ and $\left.\mathrm{C}_{\mathrm{t}}\right)$ acquired from chordwise pressure measurements can be converted into lift and drag coefficients $\left(\mathrm{C}_{1}\right.$ and $\left.\mathrm{C}_{\mathrm{d}}\right)$ for engineering calculations.

Recent studies ${ }^{14-16}$ have addressed the need for determining the angle of attack distribution from experimental data. Under the sponsorship of the National Renewable Energy Laboratory (NREL) the Lifting-Surface Prescribed-Wake (LSWT) performance-prediction methodology ${ }^{17}$, provided a unique capability for deriving angle of attack. Unsteady Aerodynamic Experiment (UAE) $C_{n}$ and $C_{t}$ data could then be converted into values of $C_{1}$ and $C_{d}$ using angle of attack distributions derived from LSWT. Through an iterative process, agreement was achieved between UAEmeasured and LSWT-predicted $\mathrm{C}_{\mathrm{n}}$ and $\mathrm{C}_{\mathrm{t}}$ radial distributions. This agreement yielded angle of attack distributions compatible with the measured post-stall 3-D aerodynamic characteristics. Unlike blade-element momentum (BEM), the LSWT methodology accounts for the induced effects of the blade configuration and those from the span-wise distribution of trailing vorticity in calculating the angle of attack distribution ${ }^{14}$.

Based on the UAE data in combination with LSWT-derived angle of attack distributions, the flow physics of inboard delayed stall was analyzed to determine how it manifests itself through enhanced $C_{1}$ and $C_{d}$. An important finding was that a midspan, rapid-drag rise governed the peak power of the UAE rotor ${ }^{16}$. Significant speculation exists as to the sequence of aerodynamic events that culminate in this midspan rapid drag raise that governs peak power.

Another finding ${ }^{14}$ was that after an angle of attack of 20 degrees the lift/drag ratio for the five radial locations at which pressure measurements were acquired essentially followed simple flat plate theory. These studies ${ }^{14-16}$ also illustrated again the difficulty of relating BEM-predicted angle of attack distributions to the post-stall 3-D aerodynamics and measured power. This finding pointed to the need for a global post-stall approach, as for instance, previously developed by Viterna ${ }^{18,19}$, for generating post stall $C_{1}$ and $C_{d}$ based on both airfoil and bladespecific stall characteristics. 
As a result of its simplicity, BEM is the most widely used theory for rotor design and analysis. Consequently, a need exists to provide better guidelines for establishing post-stall values of $C_{1}$ and $C_{d}$ that characterize the net blade aerodynamics. The present study explores and attempts to explain the 3-D aerodynamics that exists before and after peak rotor power. Further discussed is how these airfoil data characteristics relate to an inboard standing vortex (implied by the UAE measurements) followed by possible vortex bursting. With this understanding, the Viterna global post-stall approach was evaluated for various combinations of input parameters for predicting post-stall power. Guidance for the Viterna method input parameters was provided by UAE data and flat plate theory. This evaluation also included a sensitivity study of the required input parameters on the predicted power.

\section{UAE Rotor Steady State Tests}

As part of the UAE testing, steady-state data sets were acquired in the NASA Ames $24.4-\mathrm{m}$ x $36.6-\mathrm{m}(80-\mathrm{ft}$ x 120 -ft test section) wind tunnel. The rotor configuration was two-bladed, constant speed (72 rpm), upwind, and stall regulated. The 5.03-m (16.5-ft) rotor radius includes a tapered, twisted blade ${ }^{20}$ and hub (Fig. 1). The low maximum $\mathrm{C}_{1}, 21 \%$ thick, NREL S809 airfoil ${ }^{21}$ in Fig. 2 was used exclusively along the blade except for the cuff region, which transitioned from the circular root end fitting to the S809.

Values of $\mathrm{C}_{\mathrm{n}}$ and $\mathrm{C}_{\mathrm{t}}$ at the five spanwise stations $(\mathrm{r} / \mathrm{R}=0.30,0.47,0.63,0.80,0.95)$ were derived from 22 pressure taps per station. Measured $C_{n}$ and $C_{t}$ were converted to $C_{1}$ and $C_{d}$ using LSWT-derived angles of attack with the following equations:

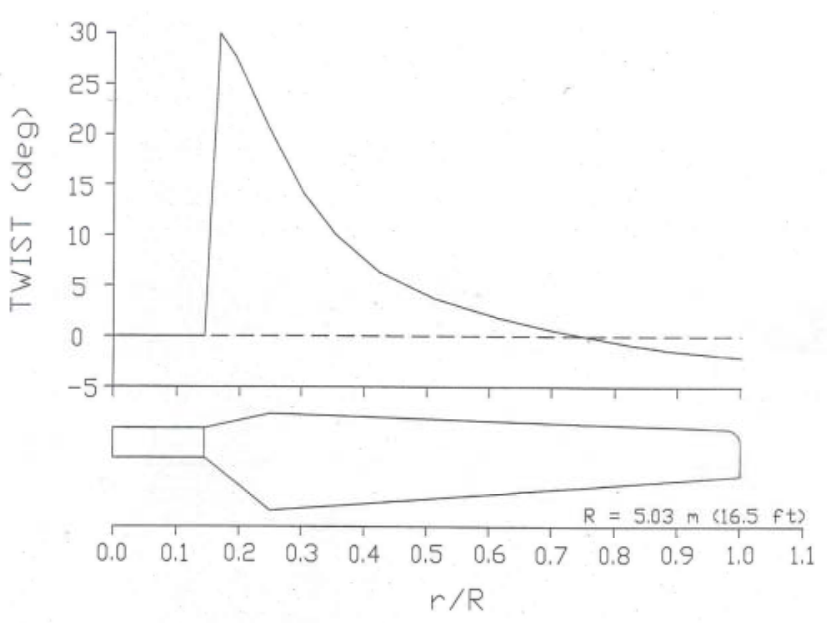

Figure 1. Chord and twist distribution for the UAE

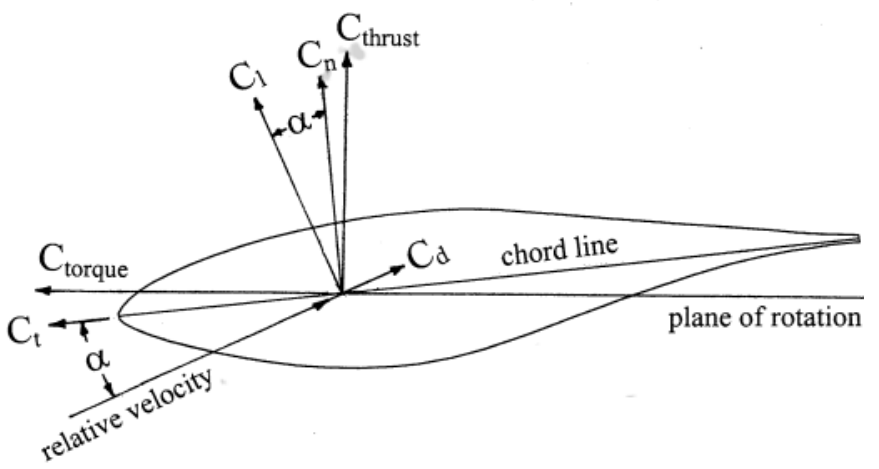

Figure 2. S809 airfoil section force coefficients.

$$
\begin{gathered}
\mathrm{C}_{1}=\frac{\frac{\mathrm{C}_{\mathrm{t}} \tan \alpha+\mathrm{C}_{\mathrm{n}}}{\sin \alpha \tan \alpha}}{1+\frac{1}{\tan ^{2} \alpha}} \\
\mathrm{C}_{\mathrm{d}}=\frac{\mathrm{C}_{\mathrm{n}}-\mathrm{C}_{1} \cos \alpha}{\sin \alpha}
\end{gathered}
$$

The resulting power curves, acquired from lowspeed shaft torque measurements, at tip pitch angles of 2, 3, and 4 degrees toward feather with respect to the airfoil chord line, are the basis for this correlation between measured and predicted power. However, airfoil characteristics $\left(\alpha, C_{l}, C_{d}\right)$ used for all the predicted power curves in this study were derived only from data associated with the 3-degree blade pitch.

\section{Stall and Post-Stall Aerodynamics}

A blade circulation contour plot was previously calculated $^{14}$ based on measured UAE $\mathrm{C}_{n}$ and $\mathrm{C}_{t}$ data and LSWT-derived $\mathrm{C}_{1}$ for wind speeds up to $16 \mathrm{~m} / \mathrm{s}$. Equation 3 was used to calculate circulation at each radial station from the local values of chord (c) and relative velocity (V).

$$
\Gamma=0.5 \mathrm{cC}_{1} \mathrm{~V}
$$

This equation, which is based on unseparated flow, is believed to be a useful, gross approximation of the circulation. Future, flow visualization studies are needed to better validate this assumption. 


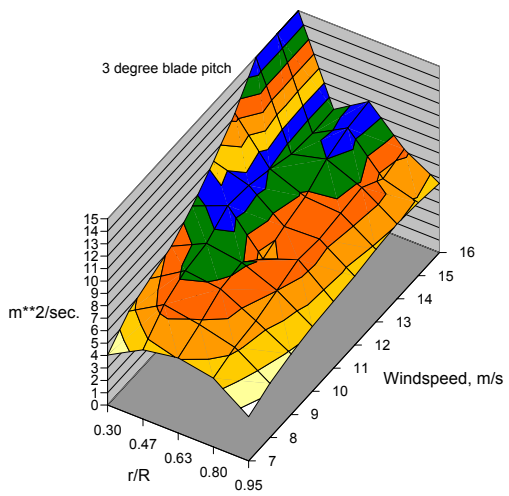

Figure 3. Circulation contour distribution.

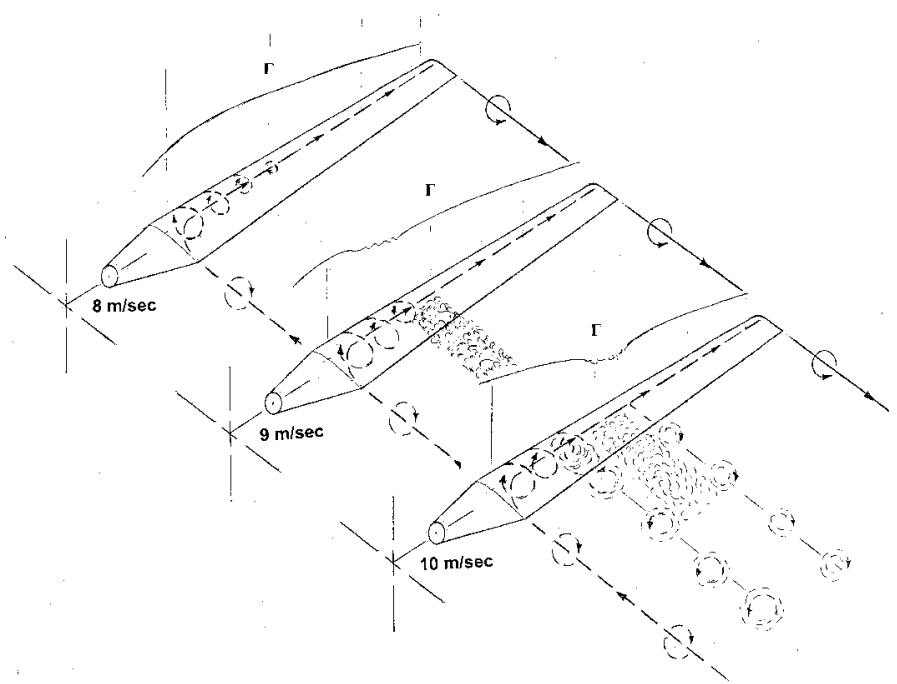

Figure 4. Blade circulation at peak rotor power.

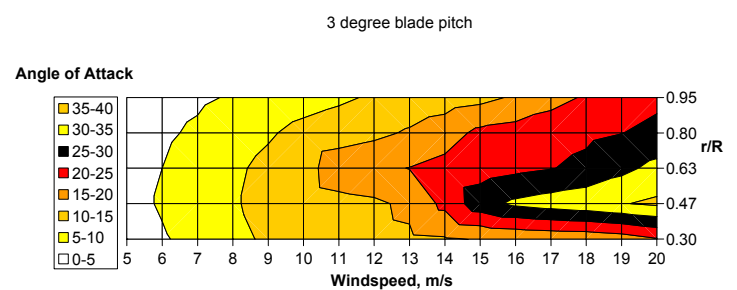

Figure 5. Angle of attack versus windspeed.
From the circulation plot (Fig. 3) and local values of $\mathrm{C}_{1}$ and $\mathrm{C}_{\mathrm{d}}$, the sequence of related aerodynamic events that occur as the twisted/tapered rotor approaches peak power (Fig. 4) can be analyzed.

At $8 \mathrm{~m} / \mathrm{s}$ a spanwise standing vortex appears to build up over the inboard half of the blade with lift coefficients at $30 \%$ and $47 \%$ radius exceeding the 2 $\mathrm{D}$ maximum of 1.0. At this wind speed the highest angle of attack occurs in the midspan region of the blade. Delayed stall effects, which drop off rapidly with radius, are minimal at midspan. Consequently, the first occurrence of local blade stall is between the wind speed of $8 \mathrm{~m} / \mathrm{s}$ and $9 \mathrm{~m} / \mathrm{s}$ at the blade's midspan location for an angle of attack of 11 degrees as calculated by LSWT $^{16}$ and illustrated in Fig. 5 . This local stall region is thought to form a midspan endplate effect for the inboard standing vortex. ${ }^{22}$ This endplate effect would likely force the inboard spanwise standing vortex into the streamwise direction. This abrupt change in direction of the vorticity could contribute to a vortex burst over the suction surface of the blade, which coincides with peak rotor power.

Indirect evidence of a vortex burst is seen in the large local drag increase starting at $9 \mathrm{~m} / \mathrm{s}$ (Fig. 6). Here, the drag coefficient, which exceeds 0.3 at 10 $\mathrm{m} / \mathrm{s}$, is three times greater than the other four radial stations. The lift coefficient associated with the high drag at $47 \%$ radius shows a local region with little change. The large drag increase results in a local midspan power decrease that corresponds to peak rotor power. ${ }^{16}$

\section{Application to Blade-Element Momentum}

Because of its simplicity BEM is the most widely used theory for rotor design and analysis. ${ }^{23}$ When used with accurate 2-D airfoil wind-tunnel data at angles of attack below stall, BEM provides reasonably accurate performance prediction. At moderate wind speeds, this capability has sufficed for blade geometry optimization for peak power coefficient. For the prediction of high wind speed peak rotor power, in the presence of local blade stall, BEM lacks the ability to model much of the flow physics that define the angle of attack distribution. Angle of attack distributions in the stall and post-stall regions are over predicted as a result of inadequate induced axial velocity. Insufficient induced axial velocity at the blade results from the uniform inflow assumption around each rotor annulus. In addition, the assumption of no interaction between adjacent rotor annuluses overlooks the midspan trailing vorticity that alters the local angle of attack. In the presence of blade stall, prescribed-wake or free-wake performance prediction methods have the potential to more 


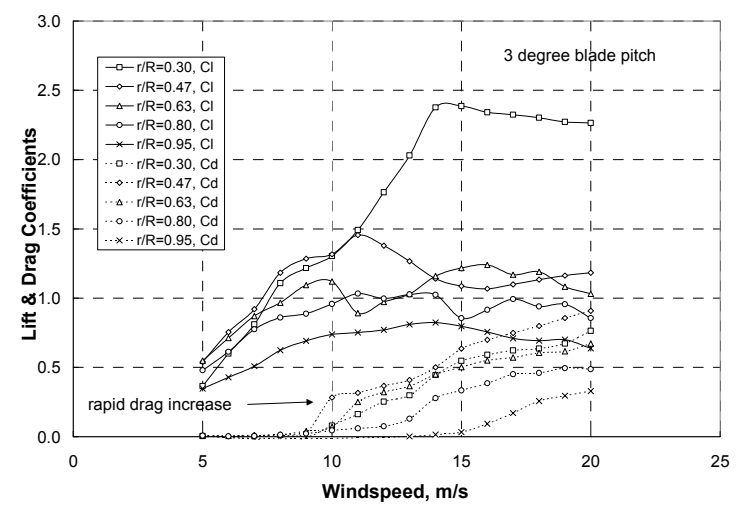

Figure 6. $C_{l}$ and $C_{d}$ versus wind speed.

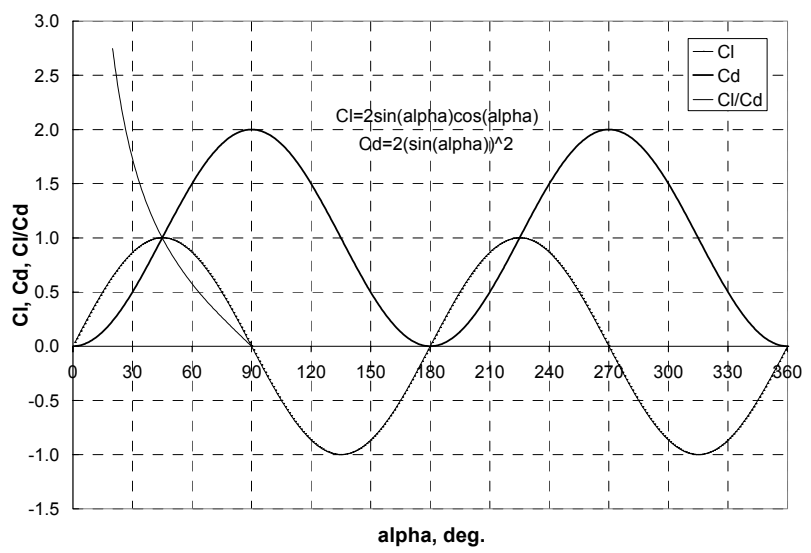

Figure 7. Flat plate theory $C_{1}, C_{d}$ and $C_{1} / C_{d}$. accurately predict the blade's angle of attack distribution.

A global post-stall airfoil data synthesization method is needed to overcome the inability of BEM to accurately predict the angle of attack distribution in the presence of stall. Such an approach should be tailored to capture the net aerodynamic effects related to the blade geometry rather than detailed flow physics characteristic of vortex wake methods.

\section{Flat Plate Theory}

The lift-to-drag ratio $\left(\mathrm{C}_{\mathrm{l}} / \mathrm{C}_{\mathrm{d}}\right)$ associated with flat plate theory provides a useful guide for nonrotating and rotating finite span wings at angles of attack following fully separated flow. For flat plate theory the variation of $\mathrm{C}_{1}, \mathrm{C}_{\mathrm{d}}$ and $\mathrm{C}_{1} / \mathrm{C}_{\mathrm{d}}$ versus angle of attack are shown in Fig. 7.

At angles of attack of 20,30 and 45 degrees, ideal flat plate theory results in $\mathrm{C}_{1} / \mathrm{C}_{\mathrm{d}}$ ratios of $2.75,1.73$, and 1.00, respectively. For non-rotating wings of different aspect ratios ${ }^{3}$ the $\mathrm{C}_{1} / \mathrm{C}_{\mathrm{d}}$ ratio closely followed flat plate theory over the angle of attack range of 30 to 90 degrees. For the rotating UAE rotor the $\mathrm{C}_{1} / \mathrm{C}_{\mathrm{d}}$ ratio at the five radial stations, at which pressure measurements were acquired closely follow flat plate theory over the angle of attack range of 20 to 90 degrees (Fig. 8). Although flat plate theory provides guidance for the post-stall $\mathrm{C}_{1} / \mathrm{C}_{\mathrm{d}}$ ratios for angles of attack in the range of 20 to 90 degrees, wind turbine power calculations are also dependent on the magnitude of the associated $C_{1}$ and $C_{d}$. The magnitudes of these parameters at 20 degrees are airfoil and blade planform dependent.

At 20 degrees the rapidly increasing drag dominates the $\mathrm{C}_{\mathrm{l}} / \mathrm{C}_{\mathrm{d}}$ ratio. At 90 degrees, where the lift is close to zero, blade planform or aspect ratio effects dictate the drag. However, for very large wind turbine blades with airfoil thicknesses of up to 40 percent, airfoil thickness also becomes a factor in determining the drag at 90 degrees. The airfoil starts acting more like an ellipse than a flat plate. Non-rotating semi-span tests ${ }^{3}$ found the maximum drag at 90 degrees to decrease with airfoil thickness over the range of 9 to 18 percent for a given aspect ratio wing.

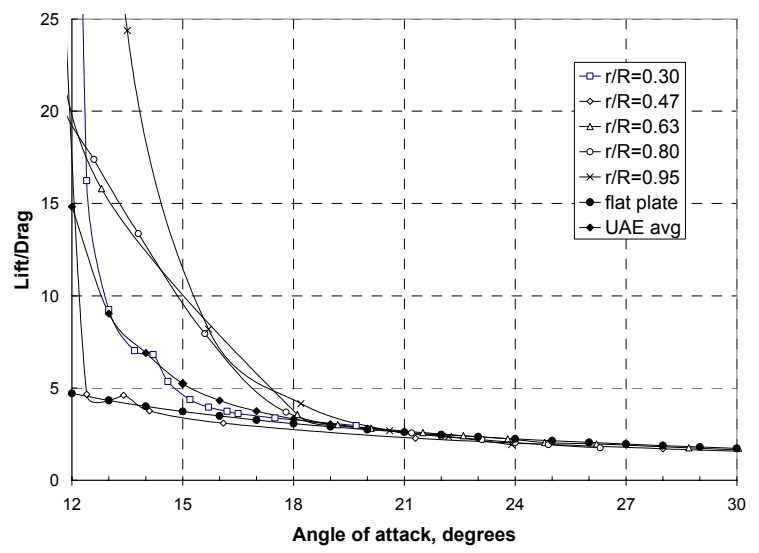

\section{Global Post Stall Model}

For BEM, the Viterna method provides a convenient global approach to relate the post-stall $\mathrm{C}_{1}$ and $\mathrm{C}_{\mathrm{d}}$ to the overall blade geometry rather than to the individual blade stations. Viterna used this post-stall approach to provide agreement between measured and predicted power for the Mod-0 and Mod-1 turbines. ${ }^{18}$ Although this method has been used for predicting post-stall airfoil characteristics, an incomplete understanding of the stall process existed at the time of its development. Based on the results from steady-state UAE measurements new guidelines are indicated for using the Viterna method.

Figure 8. UAE data and flat plate theory. 
The original Viterna equations shown below require an initial angle of attack $\left(\alpha_{\text {stall }}\right)$ with its associated drag $\left(\mathrm{C}_{\mathrm{d} \text { stall }}\right)$ and lift coefficient $\left(\mathrm{C}_{1}\right.$ stall $)$ along with a blade aspect ratio (AR). An important requirement is for the Viterna equations to satisfy flat plate theory. This condition is only satisfied when the $C_{l} / C_{d}$ at the initial angle of attack agrees with flat plate theory. Otherwise, the $\mathrm{C}_{\mathrm{l}} / \mathrm{C}_{\mathrm{d}}$ at higher angles will not agree with flat plate theory. In addition, results with the Viterna equations are largely dependent on the magnitude of the initial values of $C_{1}$ and $C_{d}$. The blade AR selection is of lesser importance. The AR is needed for determining a maximum blade drag coefficient $\left(C_{d \max }\right)$ at 90 degrees. The AR selection has an effect on post peak power prediction at wind speeds around $20 \mathrm{~m} / \mathrm{s}$. A larger AR results in greater high wind speed lift, drag and power. In this study AR selection is based on a value that provides good correlation with UAE measured rotor power at $20 \mathrm{~m} / \mathrm{s}$. The Viterna equations are as follows:

The choice of the airfoil's stall or leading-edge separation angle of attack and associated drag strongly influence predicted power just after peak power. Viterna's equations are based on using the airfoil stall angle at maximum $\mathrm{C}_{1}$ along with the associated maximum $C_{1}$ and $C_{d}$. Another option is to use the leading-edge separation angle that corresponds to the local $C_{1}$ minimum just after maximum $C_{1}$. For the S809 airfoil, the 2-D maximum $C_{1}$ of 1.06 is seen to occur at 15 degrees and to have a value of 0.68 at 20 degrees with full leading-edge separation. Associated 2-D drag coefficients for these angles are 0.1 and 0.4 , respectively. Unfortunately, neither one of these options provides a $\mathrm{C}_{1} / \mathrm{C}_{\mathrm{d}}$ for the initial condition of the Viterna equations that satisfy flat plate theory.

For predicting performance with BEM, Viterna uses the Prandtl tip and hub loss model below stall. Above stall the tip and hub loss model is turned off because finite blade length effects are thought to be accounted for through the Viterna equations. In this study, better results were obtained with the tip and hub loss models used both below and above stall. Without the tip loss model, the tip loading is always too high.

$$
\begin{aligned}
& \mathrm{C}_{\mathrm{d}_{\max }}=1.11+0.018 \mathrm{AR} \quad\left(\alpha=90^{\circ}\right) \\
& \mathrm{C}_{\mathrm{d}}=\mathrm{B}_{1} \sin ^{2} \alpha+\mathrm{B}_{2} \cos \alpha \quad\left(\alpha=15^{\circ} \text { to } 90^{\circ}\right) \\
& \mathrm{B}_{1}=\mathrm{C}_{\mathrm{dmax}} \\
& \mathrm{B}_{2}=\frac{\mathrm{C}_{\mathrm{dstall}}-\mathrm{C}_{\mathrm{dmax}} \sin ^{2} \alpha_{\text {stall }}}{\cos \alpha_{\text {stall }}} \\
& \mathrm{C}_{1}=\mathrm{A}_{1} \sin 2 \alpha+\mathrm{A}_{2} \frac{\cos ^{2} \alpha}{\sin \alpha} \quad\left(\alpha=15^{\circ} \text { to } 90^{\circ}\right)
\end{aligned}
$$

where:

$$
\begin{aligned}
& \mathrm{A}_{1}=\mathrm{B}_{1} / 2 \\
& \mathrm{~A}_{2}=\left(\mathrm{C}_{1 \text { stall }}-C_{\text {d max }} \sin \alpha_{\text {stall }} \cos \alpha_{\text {stall }}\right) \frac{\sin \alpha_{\text {stall }}}{\cos ^{2} \alpha_{\text {stall }}}
\end{aligned}
$$

\section{Post-Stall $\mathbf{C}_{\mathrm{l}}$ and $\mathrm{C}_{\mathrm{d}}$}

Guidelines are needed to quantify the $\mathrm{C}_{1}$ and $\mathrm{C}_{\mathrm{d}}$ over the angle of attack range from when the blade stalls to when flat plate theory takes over at 20 degrees. Blade-averaged values, based on UAE-derived values of $C_{1}$ and $C_{d}$, appear appropriate at 20 degrees where flat plate theory begins. To obtain these values for the UAE blade required

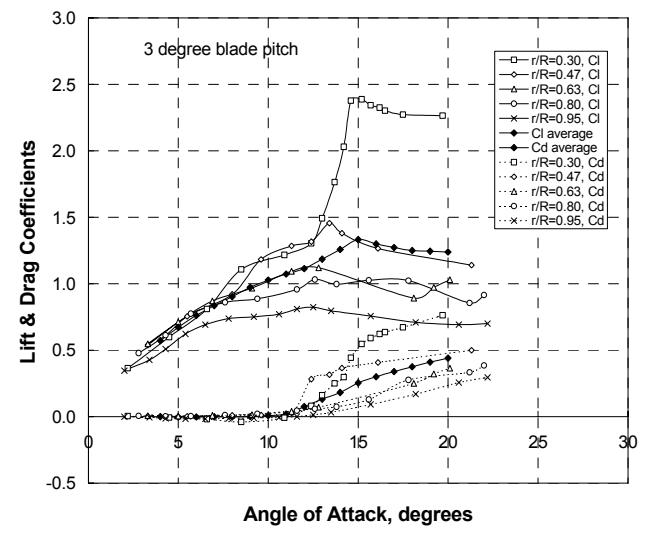

Figure 9. Blade average $C_{1}$ and $C_{d}$ relative to individual radial stations. averaging the $C_{1}$ and $C_{d}$ for the five radial stations versus angle of attack. The averaging process required a unit span weighting. As a result of the favorable spanwise spacing, the $30,47,63$, and 80 percent radial stations had a unity spanwise weighting factor, whereas the $95 \%$ station had a three-quarter spanwise weighting factor as a result of its close proximity to the tip. The average values of $C_{1}$ and $C_{d}$ are shown in Fig. 9 relative to the five individual stations.

As a result of inboard delayed stall effects, the average value of $C_{1}$ increases beyond that of 2-D data at an angle of attack from 10 degrees to 20 degrees, where $C_{1}$ avg. reaches a value of 1.24 at 20 degrees. Similarly, the $C_{d}$ avg. increases to a value of 0.44 at 20 degrees. These values provide a $\mathrm{C}_{\mathrm{l}} / \mathrm{C}_{\mathrm{d}}$ ratio at 20 degrees that is in agreement with flat plate theory. 
The blade averaged values $\left(\mathrm{C}_{1 \text { avg. }}=1.24\right.$ and $\left.\mathrm{C}_{\mathrm{d} \text { avg. }}=0.44\right)$ are now used as inputs for the Viterna equations along with a torque weighted blade $\mathrm{AR}=11.0$. This simplified weighted aspect ratio results from the blade radius divided by the local chord at $80 \%$ radius. Subsequent calculations showed that an AR of 14 provided better agreement with the measured power from $16 \mathrm{~m} / \mathrm{s}$ to $22 \mathrm{~m} / \mathrm{s}$. This implies that if a torque rated aspect ratio of 11.0 is used in Eq. 4 the constant 0.018 should be increased to 0.023 . Further study is needed to better adapt Eq. 4 for different blade geometries. Resulting Viterna predicted $C_{1}$ and $C_{d}$ for an AR of 14 are shown in Fig. 10 for the angle of attack range of 20 to 90 degrees along with the pre flat-plate values of $C_{1}$ avg. and $C_{d}$ avg. At 45 degrees, the $C_{1} / C_{d}$ ratio passes through 1.0, which satisfies flat plate theory, and the blade maximum drag coefficient at 90 degrees is 1.31 .

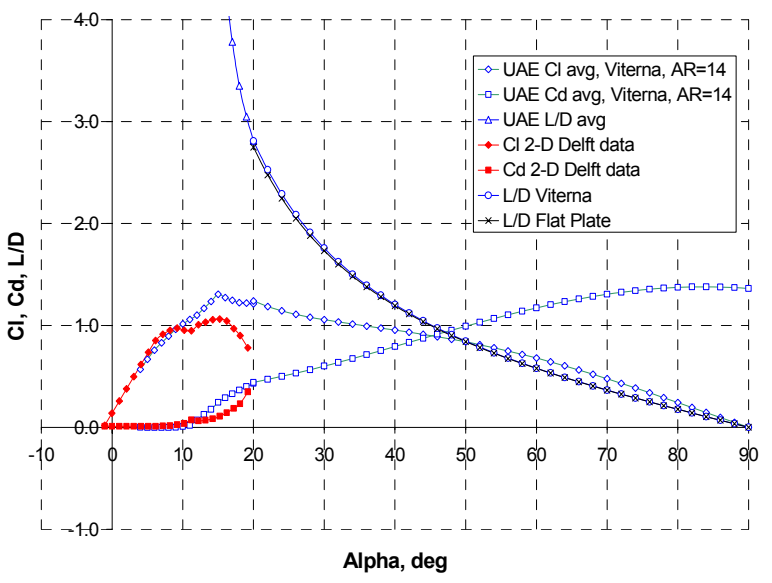

Figure 10. S809 airfoil data input for WT_Perf.

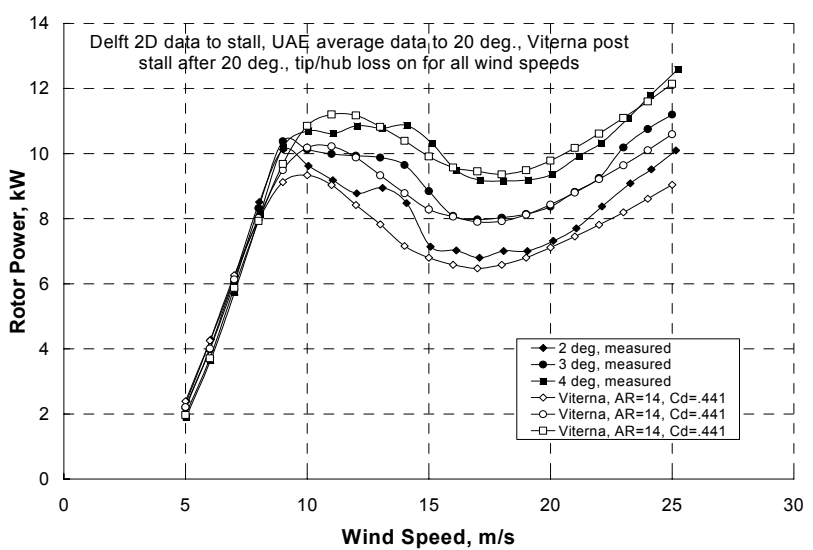

Figure 11. Comparison of UAE measured and predicted power.

\section{Predicted Rotor Power}

A comparison of UAE rotor measured and predicted power is shown in Fig. 11 for blade tip pitch angles of 2, 3, and 4 degrees. Predicted power is based on 2-D Delft data ${ }^{21}$, shown in Fig. 10, up to the stall angle of attack of 9.21 degrees. For larger angles of attack, the higher, $\mathrm{C}_{1 \text { avg. }}$ data was used up to the flat plate data angle of 20 degrees, where the Viterna equations were implemented. Steady-state measured power was derived from low speed shaft torque strain gages.

The predicted rotor power is calculated using NREL's WT_Perf BEM performance prediction code for an equally spaced, 20 segment blade. ${ }^{24}$ In this report the Prandtl tip and hub loss were employed throughout the turbine calculation range. A case can be made to turn off the tip and hub loss model when airfoil input data are derived from experimental results and the Viterna method is used after 20 degrees. However, without a tip and hub loss model the peak power at $9 \mathrm{~m} / \mathrm{s}$ is over predicted and the post-peak power is under predicted up to 17 $\mathrm{m} / \mathrm{s}$.

Using Delft 2-D data predicted results are in excellent agreement with measurements over the linear part of the power curve from $5 \mathrm{~m} / \mathrm{s}$ to $8 \mathrm{~m} / \mathrm{s}$ for all three pitch angles. Reasonable agreement is seen over the wind speed range of $9 \mathrm{~m} / \mathrm{s}$ to $25 \mathrm{~m} / \mathrm{s}$ using the post stall UAE-averaged airfoil data and the Viterna equations starting at 20 degrees. The biggest deviation is the under prediction of peak power at $9 \mathrm{~m} / \mathrm{s}$ where UAE derived drag data indicate a rapid drag increase at $47 \%$ radius. The airfoil $C_{1}$ avg. appears to be insufficient for inboard stations to adequately contribute to peak rotor power. Agreement at $20 \mathrm{~m} / \mathrm{s}$ is influenced by the input $\mathrm{AR}$ for the Viterna equations. For the UAE rotor, an aspect ratio of 14.0 provided the best agreement in predicted rotor power from 16 to 22 $\mathrm{m} / \mathrm{s}$.

A sensitivity study of the Viterna equations to a change in input parameters was conducted. As shown in Fig. 12, the aspect-ratio selection dictates the maximum drag coefficient and governs the predicted power at high wind speeds over $15 \mathrm{~m} / \mathrm{s}$. Power calculations were done for the torque weighted aspect ratios of 11, 14, and 17. The 


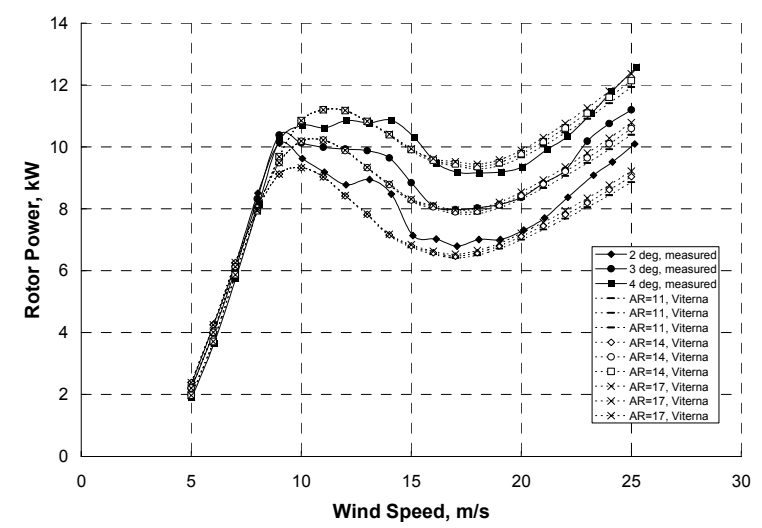

Figure 12. Aspect ratio sensitivity.

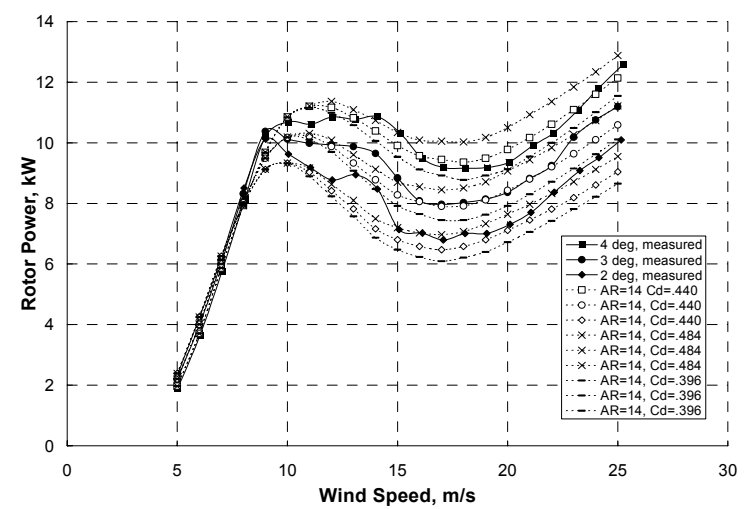

Figure 13. Viterna input $C_{l}$ and $C_{d}$ sensitivity.

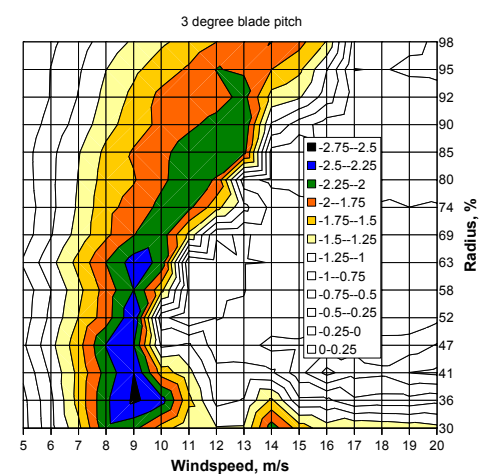

Figure 14. Pressure coefficient contour at $4 \%$ chord. predicted power at $25 \mathrm{~m} / \mathrm{s}$ increased $2 \%$ by increasing the AR by an increment of three. At this wind speed, most of the blade is in the angle of attack range of 35 to 45 degrees.

For the Viterna equation inputs at 20 degrees, a $10 \%$ increase or decrease in simultaneous input values of $\mathrm{C}_{1}$ and $C_{d}$ results in a continuous increase or decrease in the post-stall predicted power from $10 \mathrm{~m} / \mathrm{s}$ to $25 \mathrm{~m} / \mathrm{s}$ as seen in Fig. 13. At $25 \mathrm{~m} / \mathrm{s}$ this change in power is about plus and minus $5 \%$ relative to the baseline, 3-degree blade pitch.

The under predicted peak power at $9 \mathrm{~m} / \mathrm{s}$ is still dependent on the averaged UAE airfoil data prior to the Viterna equations. These results also illustrate that the post-stall bucket in the power curve is strongly dependent on choosing the correct values of $C_{1}$ and $C_{d}$ at 20 degrees. Halfway along the post-stall wind speed range, where a local minimum in power exists at 17.5 $\mathrm{m} / \mathrm{s}$, the blade angle of attack distribution lies in the 20 to 35 degree range for the 3-degree blade pitch.

\section{Standing Vortex Induced High Lift}

The inboard delayed stall high-lift effect is only partially captured in the averaged S809 airfoil data. Based on the correlation between predicted and measured power a deficiency in predicted power still exists just before peak power. This deficiency is not accounted for in the averaged airfoil data and is thought to be the result of additional lift from an inboard standing vortex located between the measured pressure distribution stations at $30 \%$ and $47 \%$ radius. Measurements from the individual $4 \%$ chordwise transducers (Fig 14), which provide intermediate point measurements at $36 \%$ and $41 \%$ radius, show the suction pressure coefficient to be greatest between these stations.

When the averaged airfoil data is enhanced for the three blade segments between $30 \%$ and $45 \%$ radius, as seen in Fig. 15, predicted power agrees closely with measurements between $8 \mathrm{~m} / \mathrm{s}$ to $10 \mathrm{~m} / \mathrm{s}$, as shown in Fig. 16. To achieve this agreement the lift curve slope for these segments has to be increased to $0.3 \mathrm{C}_{1} /$ deg relative to a 2-D value of $0.1 \mathrm{C}_{1} / \mathrm{deg}$. The UAE derived lift curve slope for the $30 \%$ radial station has been found to be of similar or greater magnitude. This high lift curve slope is used over the angle of attack range of 8 to $13 \mathrm{deg}$, and then it drops linearly to UAE-averaged $C_{1}$ at 16 degrees. This limited angle of attack range is thought to correspond to where the influence of the spanwise standing vortex is greatest followed by a vortex burst that results in a rapid $C_{1}$ drop off at higher angles. No adjustment to the averaged drag is implemented since the averaged values are thought to be somewhat adequate, but low. 


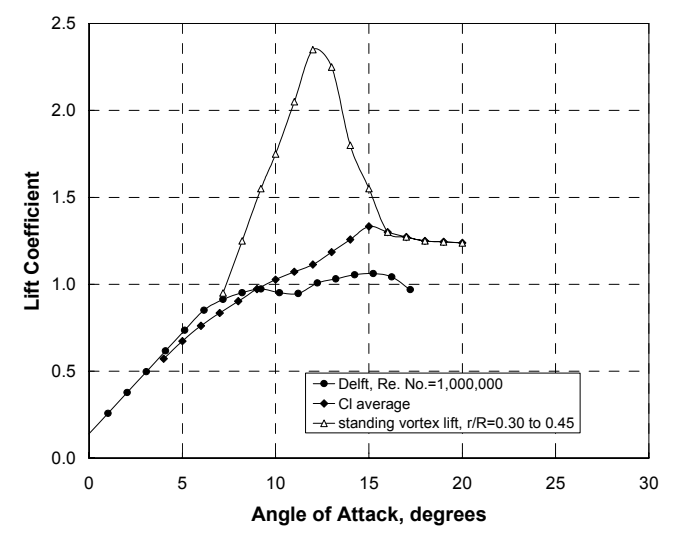

Figure 15. Inboard standing vortex enhanced lift.

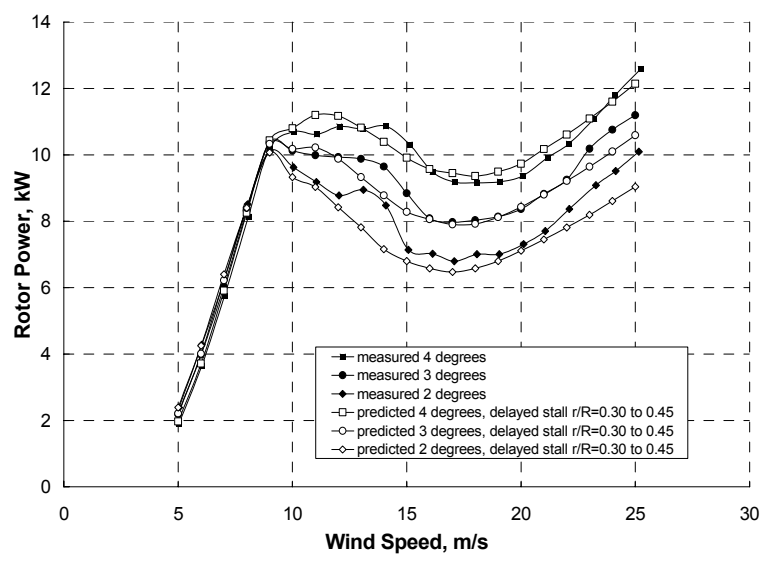

Figure 16. Effect of standing vortex induced lift.

The use of 2-D post-stall Delft airfoil data would require a greater amount of stall delay (increased $C_{1}$ and $C_{d}$ ) over a larger angle of attack range since no 3-D delayed stall effects are present in the 2-D data as there are in the UAE averaged airfoil data.

\section{Conclusion}

Delft 2-D wind tunnel data up to stall, followed by steady-state UAE-average post-stall airfoil data, and the Viterna equations guided by flat plate theory, were used with BEM theory to predict the power curve for the Phase VI UAE rotor. Agreement between measured and predicted power, using UAE average post-stall airfoil data, guided the choice of input parameters to be used with the Viterna separated flow airfoil data synthesization method.

Delft 2-D wind tunnel data provided excellent agreement between predicted and measured power up to a wind speed of $8 \mathrm{~m} / \mathrm{s}$. A simulated, local, inboard standing vortex with high induced-lift over the angle of attack range of 8 to 13 degrees was required to achieve peak power agreement for the wind speed range of $8 \mathrm{~m} / \mathrm{s}$ to $10 \mathrm{~m} / \mathrm{s}$. Using UAE $C_{1}$ avg. and $\mathrm{C}_{\mathrm{d} \text { avg. }}$ data at an angle of attack of 20 degrees resulted in good agreement with measured post stall power. Predicted post-stall power was relatively sensitive to the Viterna equation inputs of $C_{1 \text { avg }}$ and $C_{d}$ arg at 20 degrees and less sensitive to the AR value. Predicted high wind speed power from $16 \mathrm{~m} / \mathrm{s}$ to $22 \mathrm{~m} / \mathrm{s}$ was adjusted with the blade AR input to agree with measured power. The Viterna method needs to be implemented after leading-edge separation and the $\mathrm{C}_{\mathrm{l}} / \mathrm{C}_{\mathrm{d}}$ ratio for the initial conditions needs to agree with flat-plate theory.

Rotating blade, post-stall flow visualization is needed to help bridge the gap from 2-D airfoil data to the Viterna method and to better understand the midspan 3-D flow physics. The use of a water towing tank and a small-scale wind turbine emitting colored dye is a plausible experimental approach and should be explored for steady-state flow visualization of an inboard standing vortex and possible vortex bursting.

\section{Acknowledgments}

This work was supported by the U.S. Department of Energy. The assistance of L. J. Fingersh in preparing the UAE data is gratefully acknowledged.

\section{References}

${ }^{1}$ Himmelskamp, H., "Profile Investigations on a Rotating Airscrew," Dissertation Gottingen 1945, Reports and Translations No.832, Sept. 1947.

${ }^{2}$ Banks,W., and Gadd, G., "Delayed Effect of Rotation on Laminar Separation,” AIAA Journal, Vol. 1, No. 4, Apr. 1963. 
${ }^{3}$ Ostowari, C., and Naik, D., "Post-Stall Wind Tunnel Data for NACA 44XX Series Airfoil Sections," SERI/STR217-2559, Jan 1985.

${ }^{4}$ Eggers, A., and Digumarthi, R., "Approximate Scaling of Rotational Effects on Mean Aerodynamic Moments and Power Generated by CER Blades Operating in Deep Stall Flow." $11^{\text {th }}$ ASME Wind Energy Symposium, Jan 1992.

${ }^{5}$ Snel, H., Houwink, R., and Bosschers, J., " Sectional Prediction of Lift Coefficients on Rotating Wind Turbine Blades in Stall," ECN-C-93-052, Dec. 1994.

${ }^{6}$ Bosschers, J., Montgomerie, B., Brand, A.J., and van Rooy, R., "Influence of Blade Rotation on the Sectional Aerodynamics of Rotational Blades,” 22nt European Rotorcraft Forum, Sept 1996.

${ }^{7}$ Fingersh, L.J., Simms, D., Hand, M., Jager, D., Contrell, J., Robinson, M., Schreck, S., and Larwood, S., "Wind Tunnel Testing of NREL's Unsteady Aerodynamics Experiment." AIAA-2001-0035, 2001 ASME Wind Energy Symposium, Reno, NV, Jan 2001.

${ }^{8}$ Simms, D., Schreck, S, Hand, M, Fingersh, L.J., "Unsteady Aerodynamics Experiment in the NASA-Ames Wind Tunnel: A

Comparison of Predictions to Measurements," NREL/TP-500-29494, June 2001.

${ }^{9}$ Hand, M., Simms, D., Fingersh, L.J., Jager, D., Cotrell, J., Schreck, S., Larwood, S., "Unsteady Aerodynamics Experiment Phase VI: Wind Tunnel Test Configurations and Available Data Campaigns," NREL/TP-500-29955, December 2001.

${ }^{10}$ Sorensen, N.N., Michelson, J.A., and Schreck, S., "Navier-Stokes Predictions of the NREL Phase VI Rotor in the NASA Ames 80-by-120 Wind Tunnel," 2002 ASME Wind Energy Symposium, Reno, NV, Jan 2002.

${ }^{11}$ Schreck, S., and Robinson, M., "Rotational Augmentation of Horizontal Axis Wind Turbine Blade Aerodynamic Response,” AIAA -2002-0029, 2002 ASME Wind Energy Symposium, Reno, NV, Jan 2002.

${ }^{12}$ Tangler, J.L., "The Nebulous Art of Using Wind Tunnel Data for Predicting Rotor Performance," Wind Energy, 2002.

${ }^{13}$ Laino, D., and Hansen, C. A., "Current Efforts Toward Improved Aerodynamic Modeling Using the Aerodyn Subroutines," AIAA -2004-0826, 2004 ASME Wind Energy Symposium, Reno, NV, Jan 2004.

${ }^{14}$ Tangler, J.L., "Insight into a Wind Turbine Stall and Post-Stall Aerodynamics," AWEA 2003, May 2003, also WIND ENERGY, July 2004, www3.interscience.wiley.com

${ }^{15}$ Lindenburg, C., "Investigation into Rotor Blade Aerodynamics," ECN-C-03-025, June 2003.

${ }^{16}$ Gerber, B., Tangler, J.L., Duque, E., and Kocurek, J.D., "Peak and Post-Peak Power Aerodynamics from NASA Ames Phase VI Wind Turbine," Special Topic Conference 'The Science of making Torque from Wind, TU Delft, The Netherlands, April 2004.

${ }^{17}$ Kocurek, D., "Lifting Surface Performance Analysis for Horizontal Axis Wind Turbines," SERI/STR-217-3163, 1987.

${ }^{18}$ Viterna, L .A., and Corrigan, R. D., "Fixed Pitch Rotor Performance of Large Horizontal Axis Wind Turbines," DOE/NASA Workshop on Large Horizontal Axis Wind Turbines, Cleveland, Ohio, July 1981.

${ }^{19}$ Viterna, L .A., and Janetzke, D. C., "Theoretical and Experimental Power from Large Horizontal-Axis Wind Turbines," NASA TM-82944, Sept 1982.

${ }^{20}$ Giguere, P., and Selig, M.S., "Design of a Tapered and Twisted Blade for the NREL Combined Experiment Rotor," Subcontract No. XAF-4-14076-03, June 1998. 
${ }^{21}$ Somers, D.M., “Design and Experimental Results for the S809 Airfoil,” NREL/SR-440-6918, 1997.

${ }^{22}$ Wick, B.H., "Calculation of the Lift of Partially -Stalled Wings," National Aerospace Lab., NAL-TR-498T, May 1978.

${ }^{23}$ Wilson, R.E., and Walker, S. N., "Performance Analysis Program for Propeller Type Wind Turbines," Oregon State University, 1976.

${ }^{24}$ Buhl, M.L., WT_PERF User's Guide, NREL, Golden, CO, 2000. 


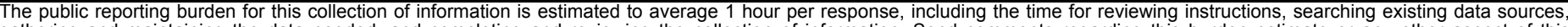

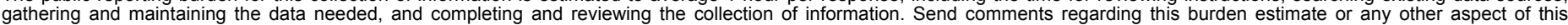

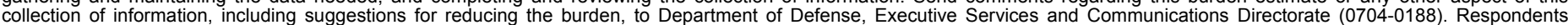

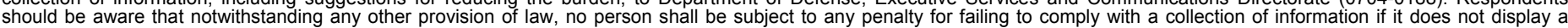

should be aware that notwithstanding

PLEASE DO NOT RETURN YOUR FORM TO THE ABOVE ORGANIZATION.

\section{REPORT DATE (DD-MM-YYYY) \\ October 2004}

4. TITLE AND SUBTITLE

Wind Turbine Post-Stall Airfoil Performance Characteristics

Guidelines for Blade-Element Momentum Methods: Preprint
3. DATES COVERED (From - To)

5a. CONTRACT NUMBER

DE-AC36-99-G010337

5b. GRANT NUMBER

5c. PROGRAM ELEMENT NUMBER

5d. PROJECT NUMBER

NREL/CP-500-36900

5e. TASK NUMBER

WER4 3110

5f. WORK UNIT NUMBER
7. PERFORMING ORGANIZATION NAME(S) AND ADDRESS(ES)

National Renewable Energy Laboratory

1617 Cole Blvd.

Golden, CO 80401-3393
8. PERFORMING ORGANIZATION REPORT NUMBER

NREL/CP-500-36900

9. SPONSORING/MONITORING AGENCY NAME(S) AND ADDRESS(ES)

10. SPONSOR/MONITOR'S ACRONYM(S) NREL

11. SPONSORING/MONITORING AGENCY REPORT NUMBER

12. DISTRIBUTION AVAILABILITY STATEMENT

National Technical Information Service

U.S. Department of Commerce

5285 Port Royal Road

Springfield, VA 22161

13. SUPPLEMENTARY NOTES

14. ABSTRACT (Maximum 200 Words)

The objective of this study was to provide post-stall airfoil data input guidelines for the prediction of peak and postpeak rotor power when using blade-element momentum theory. A steady-state data set from the Unsteady Aerodynamic Experiment (UAE) rotor test was used to provide guidelines for the development of a global post-stall method for the prediction of post-stall 3-D airfoil characteristics to be used with 2-D airfoil data. Based on these UAE data, methods to emulate the 3-D aerodynamics in the post-stall region were explored. Also suggested are experimental tests needed to better understand the 3-D flow physics and to quantify needed theory or empirical factors for a global post-stall approach to support blade-element momentum methods.

15. SUBJECT TERMS

wind energy; wind turbine; airfoil; airfoil performance; blade-element momentum

\begin{tabular}{l}
\hline \multicolumn{3}{|c|}{ 16. SECURITY CLASSIFICATION OF: } \\
\hline \begin{tabular}{l|l|l|}
\hline a. REPORT & b. ABSTRACT & c. THIS PAGE \\
Unclassified & Unclassified & Unclassified \\
& & \\
\hline
\end{tabular} \\
\hline
\end{tabular}

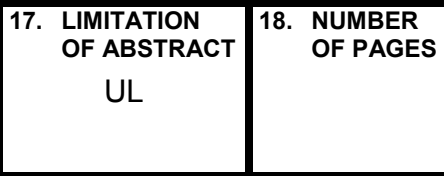

19a. NAME OF RESPONSIBLE PERSON

19b. TELEPONE NUMBER (Include area code) 